This is the pre-peer reviewed version of the following article: Awad, H., Das, U., Dimmock, J., and El-Aneed, A. (2015), Establishment of tandem mass spectrometric fingerprint of novel antineoplastic curcumin analogues using electrospray ionization. Rapid Commun. Mass Spectrom., 29, 1307-1316, which has been published in final form at doi: 10.1002/rcm.7222.

This article may be used for non-commercial purposes in accordance with Wiley Terms and Conditions for Self-Archiving.

\title{
Establishment of Tandem Mass Spectrometric Fingerprint of Novel Antineoplastic Curcumin Analogues using Electrospray Ionization
}

\author{
H. Awad ${ }^{1}$, U. Das ${ }^{1}$, J. Dimmock ${ }^{1}$, A. El-Aneed ${ }^{1 *}$ \\ 1. College of Pharmacy and Nutrition, University of Saskatchewan, Saskatoon, SK, S7N 5E5, Canada.
}

\begin{abstract}
RATIONALE

Curcumin analogues are antineoplastic agents, designed based on the structure of the spice turmeric with structural modifications aiming at enhancing potency. The goal is to identify the common tandem mass spectrometric (MS/MS) behavior of 13 novel curcumin analogues. Such knowledge is critical for their biological assessment, including metabolite identification and pharmacokinetic evaluation.
\end{abstract}

\section{METHODS}

Both detection of the protonated molecules $[\mathrm{M}+\mathrm{H}]^{+}$of the synthesized compounds and determination of their exact molecular masses were achieved with a hybrid quadrupole orthogonal time-of-flight mass spectrometer (QqTOF-MS). Low-energy collision induced dissociation (CID)-MS/MS analysis was performed using a triple quadrupole linear ion trap mass spectrometer (QqLIT-MS). Both instruments were equipped with an electrospray ionization (ESI) source. $\mathrm{MS}^{3}$ and neutral loss experiments were performed using the QqLIT-MS to confirm the genesis of the observed product ions.

\section{RESULTS}

Abundant $[\mathrm{M}+\mathrm{H}]^{+}$molecules were formed using the QqTOF-MS hybrid instrument with mass accuracies below 6 ppm. CID-MS/MS dissociation studies were centered on the piperidone ring of curcumin analogues;twelve common product ions have been identified from the fission of the various bonds within the piperidone moiety. There was a tendency for the formation of highly conjugated product ions, stabilized via resonance. The variety of the side chain substituents at the nitrogen atom resulted in side chain-specific product ions.

\section{CONCLUSIONS}

The ESI-CID-MS/MS analysis of curcumin analogues revealed a common fragmentation behavior of all tested compounds, which gave diagnostic product ions identified for each molecule. The established MS/MS behavior will be applied to determine metabolic by-products of curcumin analogues as well as to develop targeted identification/quantification methods within biological extracts. 
This is the pre-peer reviewed version of the following article: Awad, H., Das, U., Dimmock, J., and El-Aneed, A. (2015), Establishment of tandem mass spectrometric fingerprint of novel antineoplastic curcumin analogues using electrospray ionization. Rapid Commun. Mass Spectrom., 29, 1307-1316, which has been published in final form at doi: 10.1002/rcm.7222.

This article may be used for non-commercial purposes in accordance with Wiley Terms and Conditions for Self-Archiving.

\section{INTRODUCTION}

In the last few decades, the anticancer drug market showed significant growth due to the constant and crucial need for more selective, potent and, safe anticancer agents. Natural products represent one of the valuable sources for the development of novel anticancer agents. ${ }^{[1,2]}$ Biologically active compounds can either be extracted from its natural source or designed as structural analogues for naturally existing compounds. ${ }^{[1,2]}$ For example, curcumin is a natural component of the spice turmeric that showed various biological activities including anticancer, anti-inflammatory, antioxidant, and anti-microbial effects. ${ }^{[3,4]}$ The poor bioavailability of curcumin has limited its efficiency as anticancer agent. ${ }^{[5]}$ Consequently, curcumin analogues were designed by structural modification of the curcumin molecule to enhance bioavailability and potency. ${ }^{[6,7]}$

A number of curcumin analogues showed promising anticancer properties towards different cancer cell lines including melanoma and colon and pancreatic cancer cells. ${ }^{[8-11]}$ The evaluated curcumin analogues in this study were 3,5-bis(benzylidene)-4-piperidone compounds, containing the 1,5-diaryl-3-oxo-1,4-pentadienyl pharmacophore (Scheme 1A) that acts as thiol alkylator and responsible for the selective antitumor effect of these compounds. ${ }^{[1-14]}$ For more effective antitumor activity, a series of novel curcumin analogues were designed with various substituents on the aryl groups and the piperidyl nitrogen atom of the 3,5-bis(benzylidene)-4-piperidone (Scheme 1B). The aryl substituents were added to change the steric and hydrophobic properties of curcumin analogues in order to enhance their in-vivo use. ${ }^{[14]}$ On the other hand, the Nsubstituents were introduced to enhance the drug penetration into the target cells by protecting the piperidyl nitrogen atom from ionization at biological $\mathrm{pH}$, since ionized molecules are incapable to penetrate the cell membrane. ${ }^{[12]}$ In addition, the presence of N-substituents offers additional binding sites to the target cells which may increase the cytotoxicity of the drug candidate. $^{[12,13]}$

To evaluate the safety and efficiency of the newly designed compounds during preclinical and clinical studies, efficient analytical methods are required. Mass spectrometry (MS) is widely used in the drug discovery and development process based on its sensitivity, selectivity and high throughput capability. ${ }^{[15,16]}$ MS structurally characterizes the target analytes via accurate mass measurements (single stage MS analysis) as well as via collision-induced dissociation tandem mass spectrometric (CID-MS/MS) analysis. ${ }^{[17]}$ The establishment of CID-MS/MS fragmentation patterns of structurally-related compounds allows confirmation of their molecular structure and identification of their diagnostic product ions to be used subsequently for qualitative and quantitative analysis. For example, our research group illustrated a universal MS/MS dissociation behavior of a series of structurally-related cationic surfactants used as drug delivery agents. ${ }^{[18,19]}$ The data was subsequently used to develop targeted MS-based quantification methods that were employed within cellular lysate to assess the uptake and removal of these cationic lipids. ${ }^{[20,21]}$ In fact, the development of a general MS/MS dissociation behavior will allow for the prediction of the fragmentation patterns of newly synthesized compounds with structural similarities.

Recently, we investigated the ionization behavior of 13 curcumin analogues (Scheme 1B) illustrating a unique ionization mechanism that resulted in the formation of what we proposed to be positively charged $[\mathrm{M}-\mathrm{H}]^{+}$ions during single stage matrix assisted laser desorption ionizationMS (MALDI-MS) and atmospheric pressure photo ionization (APPI)-MS analysis. ${ }^{[22]}$ 
This is the pre-peer reviewed version of the following article: Awad, H., Das, U., Dimmock, J., and El-Aneed, A. (2015), Establishment of tandem mass spectrometric fingerprint of novel antineoplastic curcumin analogues using electrospray ionization. Rapid Commun. Mass Spectrom., 29, 1307-1316, which has been published in final form at doi: 10.1002/rcm.7222.

This article may be used for non-commercial purposes in accordance with Wiley Terms and Conditions for Self-Archiving.

Conversely, only the expected $[\mathrm{M}+\mathrm{H}]^{+}$species were observed during electrospray (ESI) and atmospheric pressure chemical ionization (APCI). ${ }^{[2]}$ In this subsequent study, we are evaluating the low-energy CID-ESI-MS/MS fragmentation behavior of the protonated molecules $[\mathrm{M}+\mathrm{H}]^{+}$ obtained from the curcumin analogues (Scheme 1B). Due to the wide array of structures for currently investigated curcumin analogues in the literature, ${ }^{[23-26]}$ our main aim is to create a general CID-MS/MS fingerprint that would allow identification of common CID-fragmentation patterns among the diverse structures. We identified for the first time a general MS/MS dissociation behavior that will allow precise analysis of other structurally-related compounds. In addition, our data will facilitate future studies, concerning metabolite identification as well as the development of multiple reaction monitoring (MRM) quantification methods.

\section{EXPERIMENTAL \\ Materials}

Curcumin analogues were synthesized by using previously reported synthetic methods. ${ }^{[13,14]}$ The compounds are categorized based on the nature of the $\mathrm{N}$-substituent as phosphoramidates, secondary amines, mixed amines/amides and, amides (Scheme 1B).

\section{Mass spectrometric analysis Single-stage MS analysis}

Stock solutions of each curcumin analogue were prepared to a concentration of $1 \mathrm{mg} / \mathrm{mL}$ in $100 \%$ acetonitrile (ACN). Each sample was further diluted by 500-1000× prior to single stage and tandem MS analysis. Curcumin analogues were analyzed using an AB SCIEX QSTAR ${ }^{\circledR}$ XL instrument (Foster City, California), which is a quadrupole time-of-flight hybrid mass spectrometer (QqTOF-MS) equipped with ESI source.

Samples were injected into the QqTOF-MS at flow rate of $10 \mu \mathrm{L} / \mathrm{min}$ using a Harvard Syringe Pump. The system was operated in the positive ion mode with an ionspray voltage of $5000 \mathrm{~V}$, a declustering potential of $40 \mathrm{~V}$ and, a focusing potential of $120 \mathrm{~V}$. Exact mass measurements of the curcumin analogues were performed using the QqTOF-MS with a two point external calibration. External calibration was performed prior to analyzing the curcumin analogues. Two singly charged calibration standards were used; Cesium iodide (CsI, purity 99.9\%, [M] ${ }^{+} \mathrm{m} / \mathrm{z}$ 132.9055, CAS Number 7789-17-5, Sigma-Aldrich, Oakville, ON, Canada) and Sex pheromone inhibitor iPD1 (C39H72N8O11, purity >94\%, [M+H] ${ }^{+} \mathrm{m} / \mathrm{z}$ 829.5320, CAS Number 120116-56-5, Bachem Bioscience Inc., PA, USA).

\section{Tandem mass spectrometric analysis}

Tandem mass spectrometric analysis of curcumin analogues was conducted on the AB SCIEX 4000 QTRAP $^{\circledR}$ instrument (Foster City, California), which is a hybrid triple quadrupolelinear ion trap mass spectrometer (QqLIT-MS). The MS/MS, multi-stage-MS (MS ${ }^{3}$ ), enhanced product ion scan and, neutral loss scan analysis were performed for each sample to confirm the precursor ion's structure and its fragmentation pathway. MS/MS was also acquired using the QqTOF-MS; however, the data was not as informative as minor fragmentation was obtained in comparison to the rich MS/MS data obtained by the QqLIT-MS. This is due to the fact that the QqLIT-MS allows for the accumulation of ions in the linear ion trap when applying the “enhanced” product ion scan. Such capabilities are not possible with the QqTOF-MS instrument. 
This is the pre-peer reviewed version of the following article: Awad, H., Das, U., Dimmock, J., and El-Aneed, A. (2015), Establishment of tandem mass spectrometric fingerprint of novel antineoplastic curcumin analogues using electrospray ionization. Rapid Commun. Mass Spectrom., 29, 1307-1316, which has been published in final form at doi: 10.1002/rcm.7222.

This article may be used for non-commercial purposes in accordance with Wiley Terms and Conditions for Self-Archiving.

In both instruments, collision induced dissociation (CID) was conducted in the positive ion mode with an ionspray voltage of $5500 \mathrm{~V}$, a declustering potential of 40-70 V and, a collision energy (CE) of 20-35 V using nitrogen as a collision gas. Parameters of the MS/MS analysis were optimized to ensure the formation of the product ions while maintaining the presence of the precursor ion.

\section{RESULTS AND DISCUSSION Single-stage MS analysis}

The ESI-MS (positive ion mode) full scan analysis of curcumin analogues showed abundant protonated molecules, $[\mathrm{M}+\mathrm{H}]^{+}$. The exact masses of the curcumin analogues were measured by measuring the protonated molecules masses using the ESI-QqTOF-MS, which gave mass accuracies of less than 6 ppm mass error (Table 1 in supplementary materials). This confirms the molecular structure of tested compounds, particularly when combined with MS/MS analysis, detailed below. The ability to achieve such high mass accuracy was attributed to applying external calibration of the instrument directly prior to analyzing tested compounds. In fact, such results were comparable to recent structural work in which internal calibration was employed showing mass accuracy of less than 5 ppm when analyzing cationic surfactants using the QqToFMS system. [19]

\section{Tandem mass spectrometric analysis}

The fragmentation behavior of curcumin analogues was evaluated using low-energy collision induced dissociation (CID) of ESI-QqLIT-MS in the positive ion mode. All tested curcumin analogues have the same backbone structure of 3,5-bis(benzylidene)-4-piperidone (Scheme 1A) that showed similar fragmentation behavior with bond cleavage occurring at the piperidone ring during the MS/MS analysis. The differences among curcumin analogue structures was based on the difference in the substituents of the aryl groups and the piperidyl nitrogen atom of the 3,5bis(benzylidene)-4-piperidone (Scheme 1B). Such differences resulted in specific product ions during MS/MS analysis that could be used as diagnostic product ions for the qualitative and quantitative MS/MS-analysis of these compounds. The side chain of curcumin analogues (Nsubstituents) was also dissociated during the low energy CID-MS/MS analysis. However, the side chain fragmentation did not follow a general pattern due to the dramatic differences in their chemical structures.

The detailed general fragmentation behavior of curcumin analogues was discussed in two sections; 3,5-bis(benzylidene)-4-piperidone fragmentation and side chain fragmentation to highlight the common MS/MS pathways among various curcumin analogues. It should be emphasized that we are identifying common dissociation behavior among various structures of curcumin analogues that can allow for the analysis of other compounds.

\section{3,5-bis(benzylidene)-4-piperidone fragmentation}

The curcumin analogue tagged as NC 2067 will be used as a representative model for all of the curcumin analogues. The CID- MS/MS analysis of this compound gave the highest number of common product ions, which were generated via the fragmentation of the 3,5bis(benzylidene)-4-piperidone moiety. The ESI-QqLIT-MS/MS analysis for the NC2067 showed 11 product ions (F1-11) (Figure 1). The CID-fragmentation was centered specifically on the piperidone ring (highlighted in bold blue in Figure 1A) of the 3,5-bis(benzylidene)-4-piperidone 
This is the pre-peer reviewed version of the following article: Awad, H., Das, U., Dimmock, J., and El-Aneed, A. (2015), Establishment of tandem mass spectrometric fingerprint of novel antineoplastic curcumin analogues using electrospray ionization. Rapid Commun. Mass Spectrom., 29, 1307-1316, which has been published in final form at doi: 10.1002/rcm.7222. This article may be used for non-commercial purposes in accordance with Wiley Terms and Conditions for Self-Archiving.

moiety. Accordingly, each detected product ion was formed by breaking the specific bonds of that ring illustrated in the structure within Table 1A. Table 1A shows the 12 common product ions detected during the MS/MS analysis of the 13 curcumin analogues. On the other hand, Table 2A illustrates the observed $\mathrm{m} / \mathrm{z}$ values of the common product ions during the fragmentation of the bis(benzylidene)-4-piperidone moiety of the 13 curcumin analogues with NC2067 producing 11 out of the 12 common product ions.

Initial dissociation of the piperidone ring occurs via a cleavage of the bonds (1 and 3). Two mechanisms can occur concurrently producing either the minor product ion observed at $\mathrm{m} / \mathrm{z}$ 351.1 (F1) or the highly abundant product ion observed at $\mathrm{m} / \mathrm{z} 117.0$ (F3). The proposed two mechanisms are shown in Scheme 2 in which the charge is presumably localized on the nitrogen atom. The first mechanism involves the neutral loss of $\mathrm{C}_{9} \mathrm{H}_{8}(116 \mathrm{Da})$ (Scheme 2A). This occurs via electron re-localization (shown by arrows within the structures in Scheme 2A) resulting in the species observed at $\mathrm{m} / \mathrm{z} 351.1$ where the positive charge is relocalized on the carbon of the carbonyl group. However, F1 ion is quickly converted into the more abundant highly conjugated stable diagnostic product ion at $\mathrm{m} / \mathrm{z} 349.1$ (F2) by losing a hydrogen molecule (Figure 1A).

The second mechanism involving cleavages of bonds 1 and 3 of the piperidone ring (Scheme 2B) resulted in the formation of the product ion F3 observed at $\mathrm{m} / \mathrm{z} 117.0$. In this mechanism, hydrogen rearrangement occurs; however, charge is located on the smaller species while the relatively large 350 Da species is eliminated as a cyclized neutral moiety. The F3 ion is one of the most abundant product ions that has been detected with all curcumin analogues (Table 2A). This could be due to the stable conjugated structure of this small ion that enables it to resist additional fragmentation. The mechanism shown in Scheme 2 that includes rearrangement, electron movements and cyclization is the driving principle for the formation of the majority of the piperidone-driven fragmentation.

In addition to F3, two other product ions were observed at $\mathrm{m} / \mathrm{z} 131.1$ (F4) and 143.1 (F5) by breaking the piperidone bonds at (1 and 5) and (1 and 4) respectively (Tables 1A and 2A). Similar to F3, both F4 and F5 are small ions with high conjugation within their structures (Figure 1A).

The product ion F6 observed at $\mathrm{m} / \mathrm{z} 247.1$ is formed through cleavage of bonds ( 2 and 4 ), followed by a sequential elimination of a carbonyl group $\mathrm{CO}$ and methylene $\mathrm{CH}_{2}$ resulting in the formation of ions, F7 at $\mathrm{m} / \mathrm{z} 219.1$ and F8 at $\mathrm{m} / \mathrm{z} 205.1$. It should be noted that the loss of methylene group (14 Da) is not expected; however, $\mathrm{MS}^{3}$ experiment showed that $\mathrm{F} 8 \mathrm{at} \mathrm{m} / \mathrm{z} 205.1$ is formed from the product ion F6 at $\mathrm{m} / \mathrm{z} 247.1$ (Table 2, Supplementary materials) and the only possible pathway for such dissociation (i.e. loss of $14 \mathrm{Da}$ ) is via the elimination of methylene group. Another sequential fragmentation that was observed in eight curcumin analogues includes the formation of the ion designated F9 observed at $m / z 259$, which in the case of NC2067 was formed by breaking bonds (3 and 4) and cyclization (Figure 1A \& Tables 1A and 2A). F9 ion usually loses a carbonyl group to form another product ion (F10) at $\mathrm{m} / \mathrm{z} 231.1$ that in turns losses a hydrogen molecule to generate F11 at $\mathrm{m} / \mathrm{z} 229.1$. As it can be seen among the majority of observed product ions, the dissociation behavior is driven by the formation of highly conjugated structures during the CID-MS/MS analysis of curcumin analogues.

The same fragmentation behavior of the 3,5-bis(benzylidene)-4-piperidone moiety of NC2067 was detected with other curcumin analogues (Table 2A). This behavior enables the establishment of a general fragmentation pattern for these compounds based on the CID-MS/MS of the 3,5-bis(benzylidene)-4-piperidone moiety as shown in Table 2A. However, the number of 
This is the pre-peer reviewed version of the following article: Awad, H., Das, U., Dimmock, J., and El-Aneed, A. (2015), Establishment of tandem mass spectrometric fingerprint of novel antineoplastic curcumin analogues using electrospray ionization. Rapid Commun. Mass Spectrom., 29, 1307-1316, which has been published in final form at doi: 10.1002/rcm.7222.

This article may be used for non-commercial purposes in accordance with Wiley Terms and Conditions for Self-Archiving.

detected product ions varied between curcumin analogues based on their structural differences. It can be speculated that the difference in the substituents of the aryl groups and the piperidyl nitrogen atom between curcumin analogues affect the stability of the piperidone ring and make it more or less susceptible to dissociation. For example, product ion designated as (F12) was detected with few curcumin analogues (not with NC2067) by breaking the piperidone ring bonds at (1 and 2). The absence of few product ions within some curcumin analogues could also be due to the fast conversion of these product ions into more stable species. For example, in Table 2A, the product ion (F10) was not detected with NC2315 curcumin analogue however, the product ion (F11) which is generated from (F10) by the loss of hydrogen molecule was detected with this compound. This indicates that the product ion (F10) was formed during the fragmentation of NC2315 and completely converted into F11.

To confirm the sequence of the proposed fragmentation (Figure 1A), $\mathrm{MS}^{3}$ analysis was performed (Table 2 in supplementary materials). The MS $^{3}$ experiments of NC2067 illustrated that one product ion could be formed from different sources. For example, the product ion observed at $\mathrm{m} / \mathrm{z} 143.1$ was formed from two other product ions ( $\mathrm{m} / \mathrm{z} 259.1$ and 247.1) in addition to its possible direct formation from the precursor ion. On the other hand, a unique product ion has been formed only during the MS/MS analysis of NC2067 (not shown in Table 3) with $\mathrm{m} / \mathrm{z}$ value= 189.1. In fact, $\mathrm{MS}^{3}$ analysis confirmed that this ion is a third generation product ion formed from the second generation product ion observed at $\mathrm{m} / \mathrm{z} 349.1$ via serial self-explanatory dissociation mechanism (Figure 1A).

In addition to $\mathrm{MS}^{3}$ experiments, neutral loss scans were performed to confirm the precursor ion's structure and the proposed fragmentation pathway. For example, the product ion (F3) was proposed to be directly formed by neutral loss of 350 Da from the precursor ion (467.1 Da) (Figure 1A). This pathway was confirmed by scanning the neutral loss of 350 Da during the MS/MS analysis of the protonated molecule formed from NC2067, and it confirmed that the precursor ion at $m / z 467.1$ was the sole source for the product ion (F3) at $m / z$ 117.0.

The CID-MS/MS of the protonated molecules of the curcumin analogues possessing secondary amines: at $\mathrm{m} / \mathrm{z} 336.1$ for NC2453, $\mathrm{m} / \mathrm{z} 396.1$ for NC2454, m/z 312.1 for EF24, and $\mathrm{m} / \mathrm{z}$ 308.1 for NC2128) partially followed the general pathway presented in Tables 1A and 2A by showing mainly the product ions of F3, F4 and F5. The absence of the side chain in these compounds may have resulted in the observed variations in their MS/MS dissociation behavior. Similar to other compounds, the CID-MS/MS fragmentation of the secondary amine curcumin analogues was driven by the cleavage of the piperidone ring, albeit in a different fashion than the compounds with side chains (Tables $1 \mathrm{~B}$ and $2 \mathrm{~B}$ ).

In Figure 2, the MS/MS spectrum of NC 2128 was used as a representative compound showing the direct loss of the carbonyl group from the precursor ion $\mathrm{m} / \mathrm{z} 308.0$ via breaking the 1 and 6 bonds resulting in the product ion F1' observed at $\mathrm{m} / \mathrm{z} 280.0$.. The amino group in the product ion (F1') is eliminated as ammonia (NH3) during the MS/MS of the curcumin analogue NC2128 forming the product ion (F2') at $\mathrm{m} / \mathrm{z}$ 263.0. This loss is shown in Figure 2A.

In addition, two product ions, namely F4' at $\mathrm{m} / \mathrm{z} 107.0$ and F5' at 214.1 in case of NC2128 (Figure 2 and Table 2B) were uniquely generated by the fragmentation of the benzylidene group of the 3,5-bis(benzylidene)-4-piperidone moiety via breaking the bonds I and II as shown in Table 1B. Curcumin analogues are highly conjugated species that can exist in resonance forms as shown in Figure 2A. In effect, bond I is converted from a double bond into a single bond while the double bond is located within the piperidone ring. As such, curcumin analogues can be 
This is the pre-peer reviewed version of the following article: Awad, H., Das, U., Dimmock, J., and El-Aneed, A. (2015), Establishment of tandem mass spectrometric fingerprint of novel antineoplastic curcumin analogues using electrospray ionization. Rapid Commun. Mass Spectrom., 29, 1307-1316, which has been published in final form at doi: 10.1002/rcm.7222.

This article may be used for non-commercial purposes in accordance with Wiley Terms and Conditions for Self-Archiving.

dissociated through the fission of bond I, eliminating a neutral species (201.0 Da), to yield product ion ion F4' at $m / z$ 107.0 (Figure 2A). Unlike F4', product ion F5' at $m / z$ 214.1 can undergo additional dissociating via the loss of the $\mathrm{NH}_{3}$ group producing $\mathrm{F} 6$ ' at $\mathrm{m} / \mathrm{z} 197.1$ which in turns loses the carbonyl group forming F7' at $m / z$ 169.1. Similar to F5', in which dissociation occurred at bond II, F8' at $\mathrm{m} / \mathrm{z} 201.1$ is another product ion that was formed by the cleavage of the bond II.

The loss of the aryl substituent $(\mathrm{RH})$ is one of the common product ions that have been detected with the MS/MS analysis of the secondary amines curcumin analogues. In the case of NC2128, such a loss constitutes a loss of water producing F9' at $m / z 290.0$. There are two possible mechanisms that explain the formation of F9' as presented in Figure 2A. The proposed mechanisms are dependent on the site of protonation of the precursor ion that may occur either on the basic amino group [which was presumed as the main site of protonation for this molecule] or the hydroxyl group of NC2128. In the former case, a cyclic highly conjugated F9' product ion, was proposed (Figure 2A). On the other hand, if the charge was localized on the hydroxyl group of NC2128, the loss of water yields the production of F9' species in which the positive charge is localized within the aromatic ring (Figure 2A), enhancing the stability of this ion via resonance. The mechanisms governing the formation of other product ions shown in Figure 2A are selfexplanatory such as ions observed at $\mathrm{m} / \mathrm{z} 273.0$ and 245.1. The $\mathrm{MS}^{3}$ and neutral loss experiments were performed (Table 3 in supplementary materials) to confirm the proposed fragmentation pathway as presented in Figure 2A.

Side chain fragmentation

The side chain dissociation behavior of the tested curcumin analogues was based on the structural features of each side chain. In Figure 1A, the side chain fragmentation of NC2067 was focused on the amide bond (bond is identified with an arrow in the precursor ion) with the neutral loss of the 3,5-bis(benzylidene)-4-piperidone moiety (275 Da), generating the ion of the side chain (FI) at $m / z=192.1$. Other side chain product ions (FII and FIII) were observed at $\mathrm{m} / \mathrm{z}$ 147.1 and 72.0, respectively, as shown in Figure 1A. The $\mathrm{MS}^{3}$ and the neutral loss scan experiments were performed to confirm the fragmentation pathway of these ions. For example, the product ion (FII) at $\mathrm{m} / \mathrm{z} 147.1$ was formed from the ion (FI) at $\mathrm{m} / \mathrm{z} 192.1$ and also from (F2) at $\mathrm{m} / \mathrm{z} 349.1$ (Table 2 in supplementary materials). On the other hand, a neutral loss of $395 \mathrm{Da}$ was investigated, confirming the proposed direct formation of the product ion (FIII) at $\mathrm{m} / \mathrm{z} 72$ from the precursor ion (Figure 1A).

The same fragmentation behavior of the side chain of NC2067 was also observed with other curcumin analogues that belong to the amides and mixed amine/amide categories as presented in (Table 4A in supplementary materials). The generated (FI) from NC2067 and NC2094 at m/z 192 and 191 respectively were abundant product ions characteristic to their precursor ions, to possibly serve as diagnostic product ions for these compounds. Another abundant (FI) product ion was detected at m/z 135 during the MS/MS analysis of NC2144 and NC2138 (Table 4A in supplementary materials). However, this ion cannot be used to differentiate between NC2144 and NC2138 since the structure of the product ions are identical in both cases.

In the phosphoramidate curcumin analogues (Scheme 1), the side chain product ions were formed in different fashion than the previously discussed compounds (Table 4B in supplementary materials). In this group, the product ion ( $\mathrm{Fi}$ ) was formed via the loss of the ethylene group from the side chain of the precursor ion, followed by sequential loss of other 
This is the pre-peer reviewed version of the following article: Awad, H., Das, U., Dimmock, J., and El-Aneed, A. (2015), Establishment of tandem mass spectrometric fingerprint of novel antineoplastic curcumin analogues using electrospray ionization. Rapid Commun. Mass Spectrom., 29, 1307-1316, which has been published in final form at doi: 10.1002/rcm.7222.

This article may be used for non-commercial purposes in accordance with Wiley Terms and Conditions for Self-Archiving.

ethylene group to form the (Fii) ion. The dissociation was ended by the neutral loss of water molecule forming (Fiii) ion (Table 4B in supplementary materials). In addition to the proposed side chain fragmentation, another structure was proposed for the (Fi) ion through the neutral loss of carbonyl group from the 3,5-bis(benzylidene)-4-piperidone moiety instead of side chain fragmentation.

The protonation site

The presence of different substituents on the aryl groups and the piperidyl nitrogen atom of curcumin analogues resulted in change in the basic properties of each atom in the structures of these compounds. It was not conclusive to determine which atom will show high electron density and will be able to accept a proton during the single stage positive ion mode MS analysis. However, during CID-MS/MS analysis of curcumin analogues such as NC2311 with precursor ion $[\mathrm{M}+\mathrm{H}]+=412.1$, a minor product ion at $\mathrm{m} / \mathrm{z} 394.1$ was observed (data not shown). This product ion was a result of direct loss of water molecule (18 Da), indicating that the precursor ion has a hydroxyl group which is only possible if the protonation site was the oxygen atom as presented in Scheme 3. This observation was detected with NC2311, NC2314 and NC2315 proving that oxygen atoms are possible site for protonation during the ionization of curcumin analogues.

\section{CONCLUSION}

In this work, exact mass measurement confirmed the elemental composition of the 13 novel antineoplastic curcumin analogues with mass accuracy $<6 \mathrm{ppm}$. The QqLIT-MS/MS fragmentation pattern was established for each compound confirming its chemical structure and revealing its diagnostic product ions that are characteristic for each compound. The established fragmentation patterns were confirmed via $\mathrm{MS}^{3}$ and neutral loss experiments that confirmed the proposed chemical structure of the product ions and the fragmentation pathway. A similar fragmentation behavior was observed among all tested curcumin analogues that mainly centered on the cleavage of the piperidone ring. However, such behavior was affected by the different substituents on curcumin analogues. The purpose of this work is to develop a general fragmentation behavior of all tested curcumin analogues which is illustrated in Tables $1 \mathrm{~A}$ and $2 \mathrm{~A}$.

The similarity in the fragmentation behaviors among various structures allowed for the establishment of a general fragmentation pattern for these compounds, illustrated in Tables 1 and 2. This will be beneficial in future quantitative and qualitative analysis. Such MS-fingerprint pattern can be used for the identification of these compounds or other compounds belonging to the 3,5-bis(benzylidene)-4-piperidone structural family. In addition, the use of the diagnostic product ions in quantification of curcumin analogues via multiple-reaction monitoring (MRM) analysis will ensure selectivity especially in the presence of complex matrices during preclinical and clinical studies. 
This is the pre-peer reviewed version of the following article: Awad, H., Das, U., Dimmock, J., and El-Aneed, A. (2015), Establishment of tandem mass spectrometric fingerprint of novel antineoplastic curcumin analogues using electrospray ionization. Rapid Commun. Mass Spectrom., 29, 1307-1316, which has been published in final form at doi: 10.1002/rcm.7222. This article may be used for non-commercial purposes in accordance with Wiley Terms and Conditions for Self-Archiving.

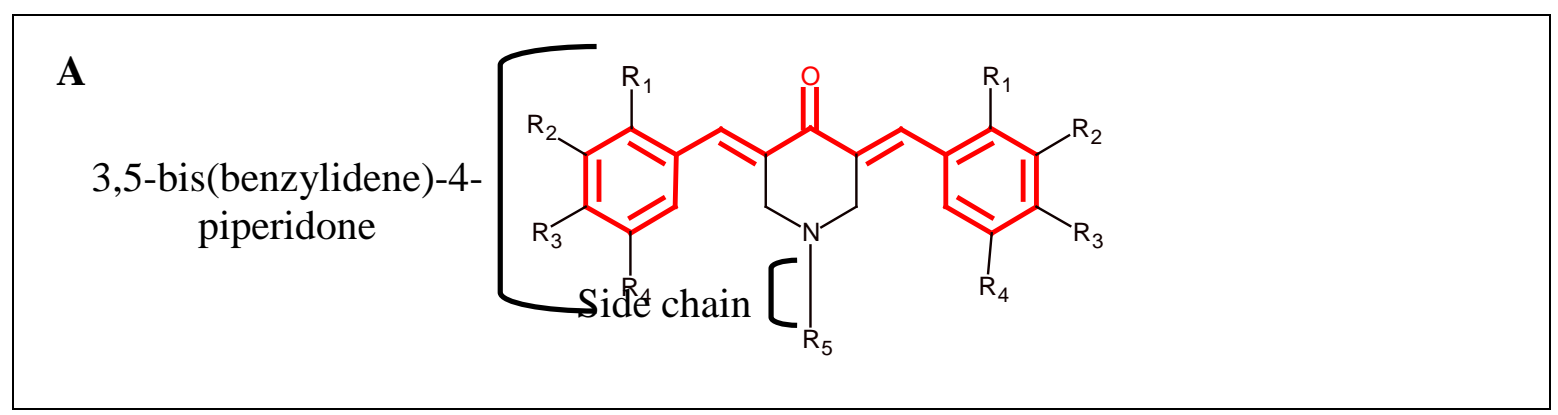


This is the pre-peer reviewed version of the following article: Awad, H., Das, U., Dimmock, J., and El-Aneed, A. (2015), Establishment of tandem mass spectrometric fingerprint of novel antineoplastic curcumin analogues using electrospray ionization. Rapid Commun. Mass Spectrom., 29, 1307-1316, which has been published in final form at doi: 10.1002/rcm.7222. This article may be used for non-commercial purposes in accordance with Wiley Terms and Conditions for Self-Archiving.

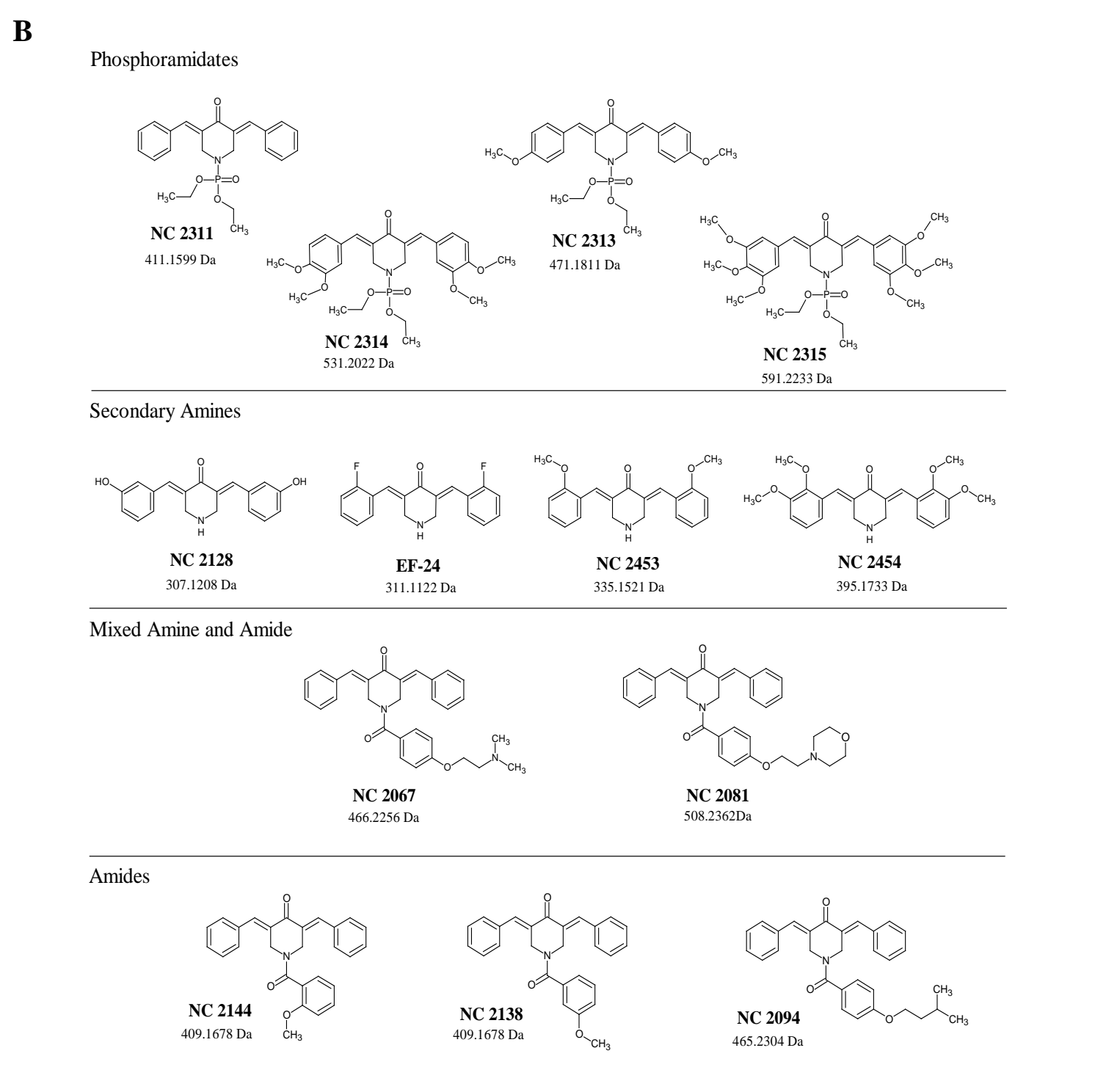

Scheme 1. Schematic representation of the 3,5-bis(benzylidene)-4-piperidones with the N-substituent as a side chain, (the 1,5-diaryl-3-oxo-1,4-pentadienyl pharmacophore is highlighted in bold red) (A). Structures and monoisotopic masses of the novel antineoplastic curcumin analogues categorized by the N-substituent into four structural families: phosphoramidates, secondary amines, mixed amines/amides and amides (B).

A

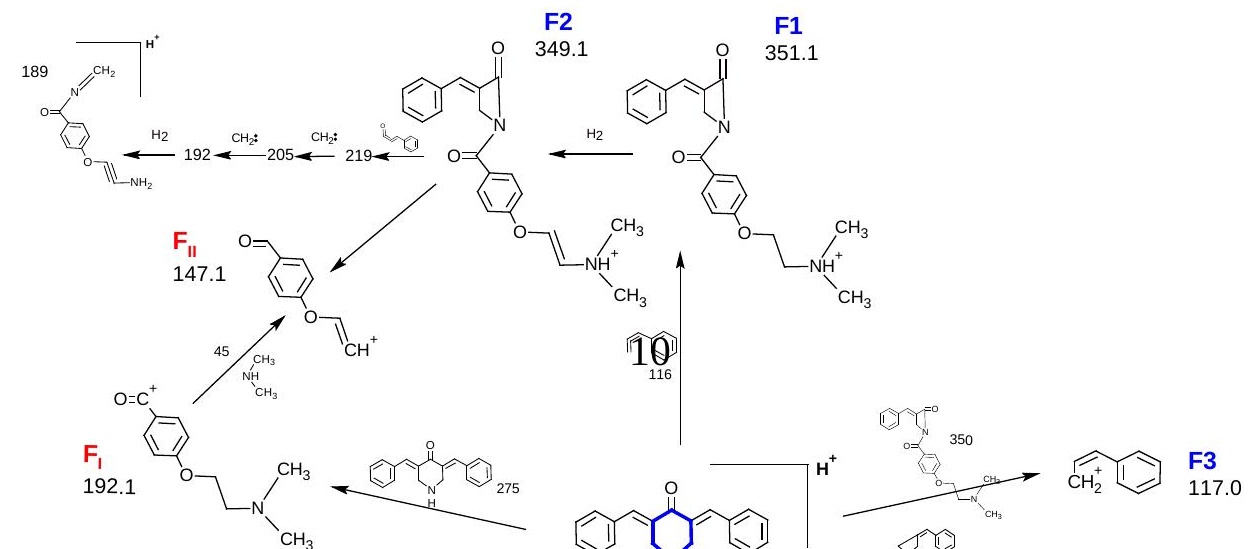


This is the pre-peer reviewed version of the following article: Awad, H., Das, U., Dimmock, J., and El-Aneed, A. (2015), Establishment of tandem mass spectrometric fingerprint of novel antineoplastic curcumin analogues using electrospray ionization. Rapid Commun. Mass Spectrom., 29, 1307-1316, which has been published in final form at doi: 10.1002/rcm.7222. This article may be used for non-commercial purposes in accordance with Wiley Terms and Conditions for Self-Archiving.

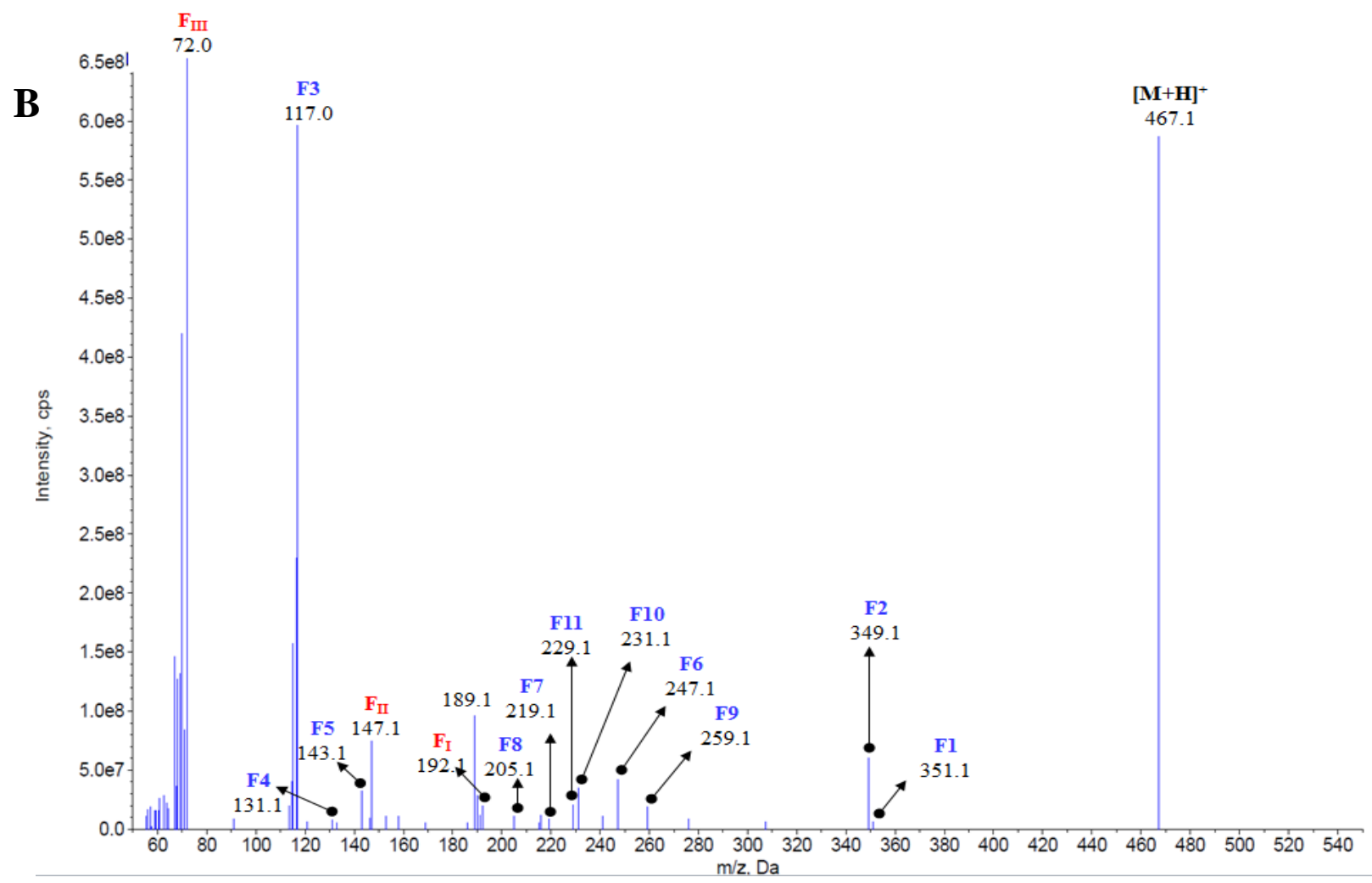

Figure 1. The proposed fragmentation pattern (A) and the ESI-QqLIT-MS/MS spectrum (B) of NC2067 (the piperidone ring of NC2067 is highlighted in bold blue and the side chain bond is identified with an arrow).

\section{A) General fragmentation scheme of all tested curcumin analogues}

\section{Product ions Broken Bonds}

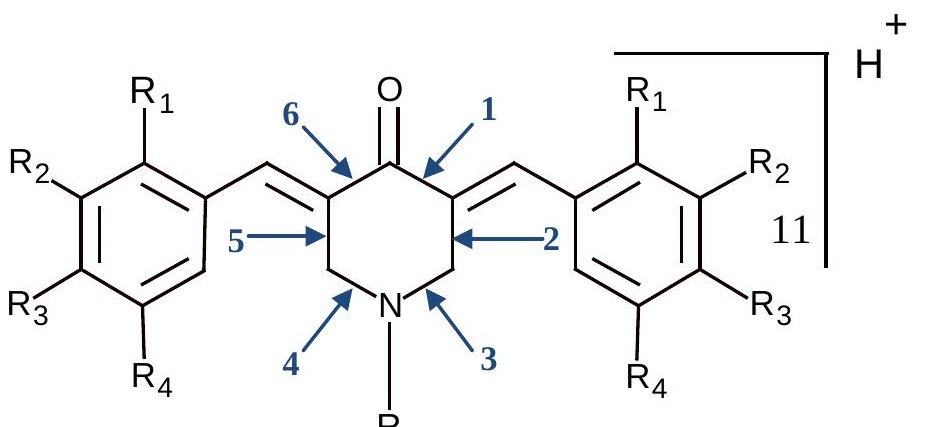

$1 \& 3$

$1 \& 3$

\begin{tabular}{l|r} 
F2 & $1 \& 3$ \\
\hline F3 & $1 \& 3$
\end{tabular}

F4

$1 \& 5$ 
This is the pre-peer reviewed version of the following article: Awad, H., Das, U., Dimmock, J., and El-Aneed, A. (2015), Establishment of tandem mass spectrometric fingerprint of novel antineoplastic curcumin analogues using electrospray ionization. Rapid Commun. Mass Spectrom., 29, 1307-1316, which has been published in final form at doi: 10.1002/rcm.7222. This article may be used for non-commercial purposes in accordance with Wiley Terms and Conditions for Self-Archiving.

\begin{tabular}{|c|c|c|}
\hline & & \\
\hline & F5 & $1 \& 4$ \\
\hline & F6 & $2 \& 4$ \\
\hline & F7 & $1,2,4 \& 6$ \\
\hline & F8 & $1,2,5 \& 6$ \\
\hline & F9 & $3 \& 4$ \\
\hline & F10 & $1,3,4 \& 6$ \\
\hline & F11 & $1,3,4 \& 6$ \\
\hline & F12 & $1 \& 2$ \\
\hline B) Special fragmentation scheme of secondary amine curcumin analogues & Product ions & Broken Bonds \\
\hline & F1' & $1 \& 6$ \\
\hline $6 \quad \mathrm{O} \quad 1$ & F2' & $1,3,4 \& 6$ \\
\hline $\mathrm{R}_{2}$ & F3' & $1,2,3,4,5 \& 6$ \\
\hline & F4' & I \\
\hline & F5' & II \\
\hline $\mathrm{R}_{3}$ & F6' & II, 3 \& 4 \\
\hline & F7' & II, 1, 3, 4 \& 6 \\
\hline${ }^{4}[\mathrm{M}+\mathrm{H}]^{+3}$ & F8' & I, 3 \& 4 \\
\hline & F9' & $\mathbf{R}$ \\
\hline
\end{tabular}

Table 1. The fragmentation sites in the 3,5-bis(benzylidene)-4-piperidone and the corresponding product ions during the ESI-MS/MS of the tested curcumin analogues (A). The fragmentation sites in the 3,5-bis(benzylidene)-4-piperidone and the corresponding product ions during the ESIMS/MS of the secondary amine curcumin analogues (B). 
This is the pre-peer reviewed version of the following article: Awad, H., Das, U., Dimmock, J., and El-Aneed, A. (2015), Establishment of tandem mass spectrometric fingerprint of novel antineoplastic curcumin analogues using electrospray ionization. Rapid Commun. Mass Spectrom., 29, 1307-1316, which has been published in final form at doi: 10.1002/rcm.7222. This article may be used for non-commercial purposes in accordance with Wiley Terms and Conditions for Self-Archiving.

A<smiles>CN(C)CCOc1ccc(C(=O)N2CC(=O)C(=Cc3ccccc3)C2)cc1</smiles><smiles>CN(C)CCOc1ccc(C(=O)NC/C(C=O)=C/c2ccccc2)cc1</smiles>
$m / z 351.1$

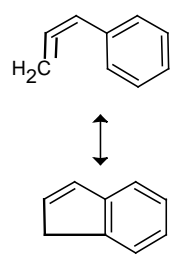

$116 \mathrm{Da}$
B
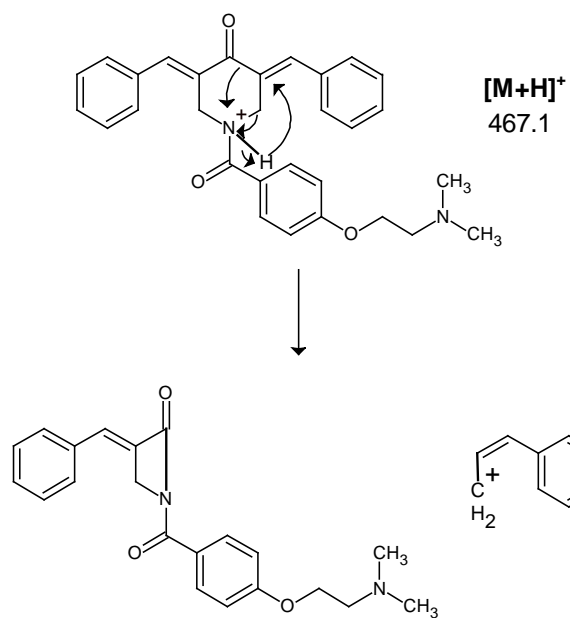

$530 \mathrm{Da}$

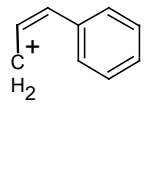

F3

Scheme 2. The two proposed mechanisms for the formation of the product ions $F 1$ at $\mathrm{m} / \mathrm{z} 351.1$ (A) and F3 at $m / z 117.0$ (B) 
This is the pre-peer reviewed version of the following article: Awad, H., Das, U., Dimmock, J., and El-Aneed, A. (2015), Establishment of tandem mass spectrometric fingerprint of novel antineoplastic curcumin analogues using electrospray ionization. Rapid Commun. Mass Spectrom., 29, 1307-1316, which has been published in final form at doi:

\begin{tabular}{|c|c|c|c|c|c|c|c|c|c|c|c|c|c|}
\hline \multicolumn{14}{|c|}{ A) The 3,5-bis(benzylidene)-4-piperidone fragmentation } \\
\hline Compound & $\begin{array}{c}\text { Precursor ion } \\
\mathbf{P}=[\mathbf{M}+\mathbf{H}]^{+}\end{array}$ & $\begin{array}{c}\text { F1 } \\
\left(\mathrm{P}-\mathrm{C}_{9} \mathrm{H}_{8}\right)\end{array}$ & $\begin{array}{c}\text { F2 } \\
(\text { F1-H })\end{array}$ & $\begin{array}{c}\text { F3 } \\
\left(\mathbf{P}-\mathrm{N}^{1}\right)\end{array}$ & $\begin{array}{c}\text { F4 } \\
\left(\mathbf{P}-\mathbf{N}^{2}\right)\end{array}$ & $\begin{array}{c}\text { F5 } \\
\left(\mathbf{P}-\mathbf{N}^{3}\right)\end{array}$ & $\begin{array}{c}\text { F6 } \\
\left(\mathrm{P}-\mathrm{N}^{4}\right)\end{array}$ & $\begin{array}{c}\text { F7 } \\
\text { (F6-CO) }\end{array}$ & $\begin{array}{c}\text { F8 } \\
\left(\mathrm{F} 7-\mathrm{CH}_{2}\right)\end{array}$ & $\begin{array}{c}\text { F9 } \\
\left(\mathbf{P}-\mathrm{N}^{5}\right)\end{array}$ & $\begin{array}{c}\text { F10 } \\
\text { (F9-CO) }\end{array}$ & $\begin{array}{c}\text { F11 } \\
\left(\text { F10- } \mathbf{H}_{2}\right)\end{array}$ & $\begin{array}{c}\text { F12 } \\
\left(\mathbf{P}-\mathbf{N}^{6}\right)\end{array}$ \\
\hline 2311 & 412.2 & 296 & - & 117 & 131 & 143 & 247 & 219 & 205 & 259 & 231 & 229 & 308 \\
\hline 2313 & 472.2 & - & - & 147 & 161 & - & 307 & - & - & - & - & - & - \\
\hline 2314 & 532.2 & - & - & 177 & 191 & 203 & - & - & - & 379 & - & - & 368 \\
\hline 2315 & 592.2 & - & - & 207 & 221 & 233 & 427 & - & - & 439 & - & 409 & 398 \\
\hline 2067 & 467.2 & 351 & 349 & 117 & 131 & 143 & 247 & 219 & 205 & 259 & 231 & 229 & - \\
\hline 2081 & 509.2 & - & 391 & 117 & - & 143 & 247 & 219 & 205 & 259 & 231 & 229 & - \\
\hline 2144 & 410.2 & 294 & - & 117 & 131 & 143 & 247 & 219 & 205 & 259 & 231 & 229 & - \\
\hline 2138 & 410.2 & - & - & 117 & 131 & 143 & 247 & 219 & 205 & 259 & 231 & 229 & 306 \\
\hline 2094 & 466.2 & - & - & 117 & - & - & 247 & 219 & 205 & 259 & 231 & 229 & - \\
\hline 2453 & 336.2 & - & - & 147 & 161 & 173 & - & - & - & - & - & - & - \\
\hline 2454 & 396.2 & - & - & 177 & 191 & 203 & - & - & - & 379 & - & - & - \\
\hline EF24 & 312.2 & - & - & 135 & 149 & 161 & 283 & - & - & - & - & - & - \\
\hline 2128 & 308.2 & - & 174 & 133 & 147 & 159 & - & - & - & 291 & - & - & - \\
\hline \multicolumn{14}{|c|}{ B) The fragmentation of secondary amines curcumin analogues } \\
\hline Compound & $\begin{array}{c}\text { Precursor ion } \\
\mathbf{P}=[\mathbf{M}+\mathbf{H}]^{+}\end{array}$ & $\begin{array}{c}\text { F1' } \\
(\mathrm{P}-\mathrm{CO})\end{array}$ & $\begin{array}{c}\mathrm{F}^{\prime} \\
\left(\mathrm{F}^{\prime}-\mathrm{NH}_{3}\right)\end{array}$ & $\begin{array}{c}\text { F3' } \\
\left(\text { F2' }^{\prime}-\mathrm{C}_{2} \mathrm{H}_{2}\right)\end{array}$ & $\begin{array}{c}\text { F4' } \\
\left(\mathrm{P}-\mathrm{X}_{1}\right)\end{array}$ & $\begin{array}{c}\text { F5' }^{\prime} \\
\left(\mathbf{P}-\mathbf{X}_{2}\right)\end{array}$ & $\begin{array}{c}\text { F6' }^{\prime} \\
\left(\text { F5'-NH }^{\prime}\right)\end{array}$ & $\begin{array}{c}\text { F7' } \\
\text { (F6'-CO) }\end{array}$ & F8' & $\begin{array}{c}\text { F9' }^{\prime} \\
\text { (P-RH) }\end{array}$ & & & \\
\hline 2453 & 336.2 & 308 & 291 & 265 & 121 & 228 & 211 & 183 & 215 & 304 & & & \\
\hline 2454 & 396.2 & 368 & 351 & 325 & 151 & 258 & 241 & 213 & 245 & 364 & & & \\
\hline EF24 & 312.2 & 284 & 267 & - & 109 & 216 & - & 171 & 203 & 292 & & & \\
\hline 2128 & 308.2 & 280 & 263 & 237 & 107 & 214 & 197 & 169 & 201 & 290 & & & \\
\hline
\end{tabular}

$\mathbf{N}^{1}=\mathrm{C}_{10} \mathrm{H}_{4} \mathrm{NO}+\mathrm{R}_{1}+\mathrm{R}_{2}+\mathrm{R}_{3}+\mathrm{R}_{4}+\mathrm{R}_{5}$

$\mathbf{N}^{2}=\mathrm{C}_{10} \mathrm{H}_{6} \mathrm{~N}+\mathrm{R}_{1}+\mathrm{R}_{2}+\mathrm{R}_{3}+\mathrm{R}_{4}+\mathrm{R}_{5}$
$\mathbf{N}^{3}=\mathrm{C}_{9} \mathrm{H}_{6} \mathrm{~N}+\mathrm{R}_{1}+\mathrm{R}_{2}+\mathrm{R}_{3}+\mathrm{R}_{4}+\mathrm{R}_{5}$ $\mathrm{N}^{4}=\mathrm{CH}_{2} \mathrm{~N}+\mathrm{R}_{5}$
$\mathbf{N}^{5}=\mathrm{NH}_{2}+\mathrm{R}_{5}$

$\mathbf{N}^{6}=\mathrm{C}_{8} \mathrm{H}_{4}+\mathrm{R}_{1}+\mathrm{R}_{2}+\mathrm{R}_{3}+\mathrm{R}_{4}$
$\mathbf{X}_{1}=\mathrm{C}_{12} \mathrm{H}_{7} \mathrm{NO}+\mathrm{R}_{1}+\mathrm{R}_{2}+\mathrm{R}_{3}+\mathrm{R}_{4}$ $\mathbf{X}_{2}=\mathrm{C}_{6} \mathrm{H}_{2}+\mathrm{R}_{1}+\mathrm{R}_{2}+\mathrm{R}_{3}+\mathrm{R}_{4}$

Table 2. The product ions of the 3,5-bis(benzylidene)-4-piperidone moiety during the ESI-MS/MS of all tested curcumin analogues (A). Special product ions were formed during the ESI-MS/MS of secondary amines curcumin analogues (B). 
This is the pre-peer reviewed version of the following article: Awad, H., Das, U., Dimmock, J., and El-Aneed, A. (2015),

A Establishment of tandem mass spectrometric fingerprint of novel antineoplastic curcumin analogues using electrospray ionization. Rapid Commun. Mass Spectrom., 29, 1307-1316, which has been published in final form at doi: 10.1002/rcm.7222. This article may be used for non-commercial purposes in accordance with Wiley Terms and Conditions for Self-Archiving.

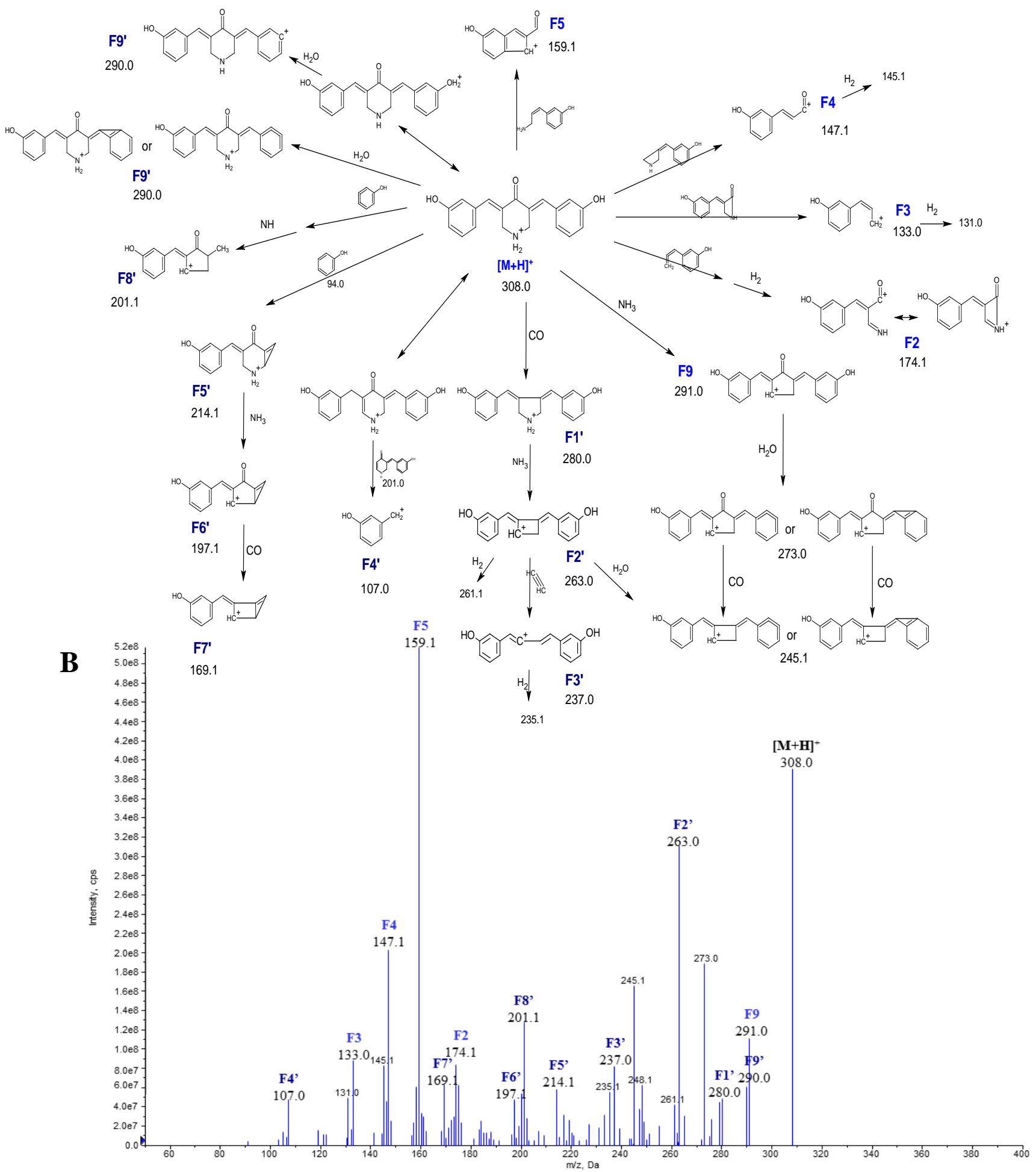

Figure 2. The proposed fragmentation pattern (A) and the ESI-QqLIT-MS/MS spectrum (B) of NC 2128 secondary amine curcumin analogue 
This is the pre-peer reviewed version of the following article: Awad, H., Das, U., Dimmock, J., and El-Aneed, A. (2015), Establishment of tandem mass spectrometric fingerprint of novel antineoplastic curcumin analogues using electrospray ionization. Rapid Commun. Mass Spectrom., 29, 1307-1316, which has been published in final form at doi: 10.1002/rcm.7222. This article may be used for non-commercial purposes in accordance with Wiley Terms and Conditions for Self-Archiving.

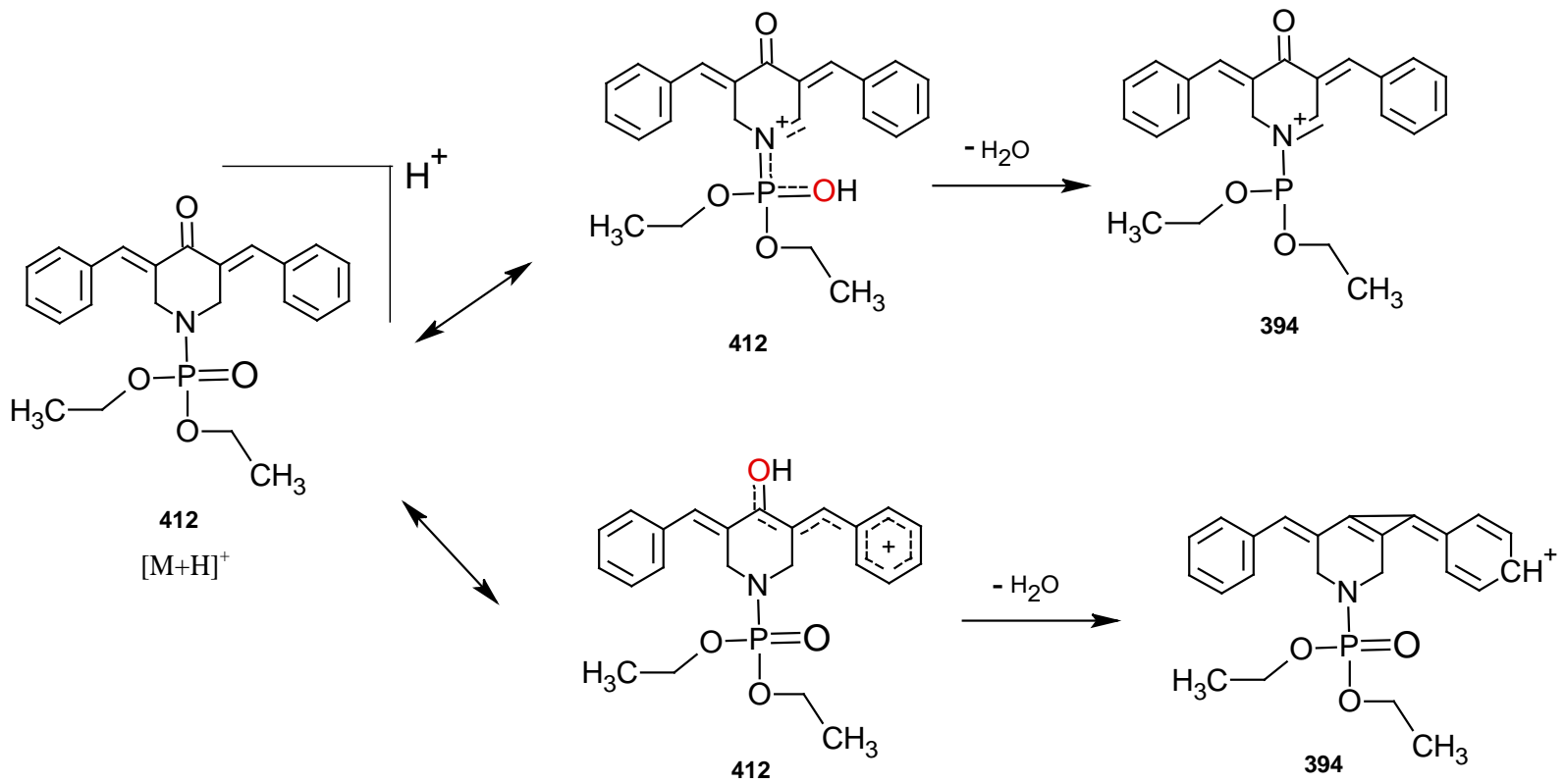

Scheme 3. The direct loss of water molecule from the precursor ion of NC2311 (412.1) and the formation of a product ion with $\mathrm{m} / \mathrm{z}$ value at 394.1 
This is the pre-peer reviewed version of the following article: Awad, H., Das, U., Dimmock, J., and El-Aneed, A. (2015), Establishment of tandem mass spectrometric fingerprint of novel antineoplastic curcumin analogues using electrospray ionization. Rapid Commun. Mass Spectrom., 29, 1307-1316, which has been published in final form at doi: 10.1002/rcm.7222.

This article may be used for non-commercial purposes in accordance with Wiley Terms and Conditions for Self-Archiving.

\section{REFERENCES}

[1] M. Gordaliza. Natural products as leads to anticancer drugs. Clinical and Translational Oncology 2007, 9, 767.

[2] S. Coseri. Natural products and their analogues as efficient anticancer drugs. Mini reviews in medicinal chemistry 2009, 9, 560.

[3] B. B. Aggarwal, A. Kumar, A. C. Bharti. Anticancer potential of curcumin: preclinical and clinical studies. Anticancer Res 2003, 23, 363.

[4] R. K. Maheshwari, A. K. Singh, J. Gaddipati, R. C. Srimal. Multiple biological activities of curcumin: a short review. Life sciences 2006, 78, 2081.

[5] P. Anand, A. B. Kunnumakkara, R. A. Newman, B. B. Aggarwal. Bioavailability of curcumin: problems and promises. Molecular pharmaceutics 2007, 4, 807.

[6] S. Padhye, D. Chavan, S. Pandey, J. Deshpande, K. V. Swamy, F. H. Sarkar. Perspectives on chemopreventive and therapeutic potential of curcumin analogs in medicinal chemistry. Mini reviews in medicinal chemistry 2010, 10, 372.

[7] P. Anand, S. G. Thomas, A. B. Kunnumakkara, C. Sundaram, K. B. Harikumar, B. Sung, S. T. Tharakan, K. Misra, I. K. Priyadarsini, K. N. Rajasekharan. Biological activities of curcumin and its analogues (Congeners) made by man and Mother Nature. Biochemical pharmacology 2008, 76, 1590.

[8] G. P. Nagaraju, S. Zhu, J. Wen, A. B. Farris, V. N. Adsay, R. Diaz, J. P. Snyder, S. Mamoru, B. F. El-Rayes. Novel synthetic curcumin analogues EF31 and UBS109 are potent DNA hypomethylating agents in pancreatic cancer. Cancer letters 2013, 341, 195.

[9] S. S. Kanwar, Y. Yu, J. Nautiyal, B. B. Patel, S. Padhye, F. H. Sarkar, A. P. Majumdar. Difluorinated-curcumin (CDF): a novel curcumin analog is a potent inhibitor of colon cancer stem-like cells. Pharmaceutical research 2011, 28, 827.

[10] F. Faião-Flores, J. A. Q. Suarez, S. S. Maria-Engler, V. Soto-Cerrato, R. Pérez-Tomás, D. A. Maria. The curcumin analog DM-1 induces apoptotic cell death in melanoma. Tumor Biology 2013, 34, 1119.

[11] S. Das, U. Das, D. Michel, D. K. Gorecki, J. R. Dimmock. Novel 3, 5-bis (arylidene)-4piperidone dimers: Potent cytotoxins against colon cancer cells. European journal of medicinal chemistry 2013, 64, 321.

[12] U. Das, R. K. Sharma, J. R. Dimmock. 1, 5-Diaryl-3-oxo-1, 4-pentadienes: A case for antineoplastics with multiple targets. Current medicinal chemistry 2009, 16, 2001.

[13] U. Das, J. Alcorn, A. Shrivastav, R. K. Sharma, E. De Clercq, J. Balzarini, J. R. Dimmock. Design, synthesis and cytotoxic properties of novel 1-[4-(2-alkylaminoethoxy) phenylcarbonyl]-3, 5-bis (arylidene)-4-piperidones and related compounds. European journal of medicinal chemistry 2007, 42, 71.

[14] S. Das, U. Das, P. Selvakumar, R. K. Sharma, J. Balzarini, E. De Clercq, J. Molnár, J. Serly, Z. Baráth, G. Schatte. 3, 5-Bis (benzylidene)-4-oxo-1-phosphonopiperidines and Related Diethyl Esters: Potent Cytotoxins with Multi-Drug-Resistance Reverting Properties. ChemMedChem 2009, 4, 1831.

[15] Y. Hsieh, W. Korfmacher. The role of hyphenated chromatography-mass spectrometry techniques in exploratory drug metabolism and pharmacokinetics. Current pharmaceutical design 2009, 15, 2251. 
This is the pre-peer reviewed version of the following article: Awad, H., Das, U., Dimmock, J., and El-Aneed, A. (2015), Establishment of tandem mass spectrometric fingerprint of novel antineoplastic curcumin analogues using electrospray ionization. Rapid Commun. Mass Spectrom., 29, 1307-1316, which has been published in final form at doi: 10.1002/rcm.7222.

This article may be used for non-commercial purposes in accordance with Wiley Terms and Conditions for Self-Archiving.

[16] W. Korfmacher, K. Yu. Mass Spectrometry: The Premier Analytical Tool for DMPK Scientists in a Drug Discovery Environment. LC GC North America 2012, 30, 640.

[17] M. Donkuru, J. M. Chitanda, R. E. Verrall, A. El-Aneed. Multi-stage tandem mass spectrometric analysis of novel $\beta$-cyclodextrin-substituted and novel bis-pyridinium gemini surfactants designed as nanomedical drug delivery agents. Rapid Communications in Mass Spectrometry 2014, 28, 757.

[18] J. Buse, I. Badea, R. E. Verrall, A. El-Aneed. Tandem mass spectrometric analysis of the novel gemini surfactant nanoparticle families G12-s and G18: 1-s. Spectroscopy Letters 2010, 43, 447.

[19] J. Buse, I. Badea, R. E. Verrall, A. El-Aneed. Tandem mass spectrometric analysis of novel diquaternary ammonium gemini surfactants and their bromide adducts in electrospray-positive ion mode ionization. Journal of Mass Spectrometry 2011, 46, 1060.

[20] J. Buse, I. Badea, R. E. Verrall, A. El-Aneed. A general liquid chromatography tandem mass spectrometry method for the quantitative determination of diquaternary ammonium gemini surfactant drug delivery agents in mouse keratinocytes' cellular lysate. Journal of Chromatography A 2013, 1294, 98.

[21] J. Buse, R. W. Purves, R. E. Verrall, I. Badea, H. Zhang, C. C. Mulliga, K. M. Peru, J. Bailey, J. V. Headley, A. El-Aneed. The development and assessment of high-throughput mass spectrometry-based methods for the quantification of a nanoparticle drug delivery agent in cellular lysate. Journal of Mass Spectrometry 2014, 49, 1171.

[22] H. Awad, M. J. Stoudemayer, L. Usher, I. J. Amster, A. Cohen, U. Das, R. M. Whittal, J. Dimmock, A. El-Aneed. The Unexpected Formation of $[\mathrm{M}-\mathrm{H}]^{+}$Species During MALDI and Dopant free-APPI MS Analysis of Novel Antineoplastic Curcumin Analogues. Journal of Mass Spectrometry 2014, 49, 1139.

[23] Z.-Y. Du, X. Wei, M.-T. Huang, X. Zheng, Y. Liu, A. H. Conney, K. Zhang. Antiproliferative, anti-inflammatory and antioxidant effects of curcumin analogue A2. Archives of pharmacal research 2013, 36, 1204.

[24] B. Chen, Z. Zhu, M. Chen, W. Dong, Z. Li. Three-dimensional quantitative structureactivity relationship study on antioxidant capacity of curcumin analogues. Journal of Molecular Structure 2014, 1061, 134.

[25] Y.-Q. Xia, Wei1, X.-Y. , W.-L. Li, K. Kanchana, C.-C. Xu, D.-H. Chen, P.-H. Chou, R. Jin, J.-Z. Wu, G. Liang. Curcumin Analogue A501 induces G2/M Arrest and Apoptosis in Non-small Cell Lung Cancer Cells. Asian Pacific Journal of Cancer Prevention 2014, 15, 6893.

[26] S. Zhu, T. W. Moore, X. Lin, N. Morii, A. Mancini, R. B. Howard, D. Culver, R. F. Arrendale, P. Reddy, T. J. Evers. Synthetic curcumin analog EF31 inhibits the growth of head and neck squamous cell carcinoma xenografts. Integrative Biology 2012, 4, 633. 